\title{
Pharmacokinetics of Paclitaxel and Metabolites in a Randomized Comparative Study in Platinum-Pretreated Ovarian Cancer Patients
}

\author{
By Manon T. Huizing, Anther C.F. Keung, Hilde Rosing, Victor van der Kuii, Wim W. ten Bokkel Huinink, \\ Ingrid M. Mandjes, A. (Ria) C. Dubbelman, Herbert M. Pinedo, and Jos H. Beijnen
}

\begin{abstract}
Purpose: To investigate the pharmacokinetics and pharmacodynamics of paclitaxel in a randomized comparative study with four different treatment arms in patients with platinum-pretreated ovarian carcinoma.

Patients and Methods: Eighteen patients were entered onto this study in which paclitaxel was administered at a high dose of $175 \mathrm{mg} / \mathrm{m}^{2}$ versus a low dose of $135 \mathrm{mg} / \mathrm{m}^{2}$ on a 3- or 24-hour infusion schedule. A solid-phase extraction technique for sample pretreatment followed by a reverse-phase high-performance liquid chromatographic (HPLC) assay was used for analysis of plasma.

Results: Grade 3 neutropenia occurred in all four treatment arms. However, it was more severe on the 24-hour infusion schedule. Paclitaxel concentrations as low as $0.012 \mu \mathrm{mol} / \mathrm{L}$ were measured with the HPLC assay. With this low quantitation threshold, we found the plasma disappearance of paclitaxel to be triphasic, with half-lives $t_{1 / 2}(\alpha), t_{1 / 2}(\beta)$, and $t_{1 / 2}(\gamma)$ mean values for the different treatment arms of 0.19 hours (range, 0.01 to 0.4 ), 1.9 hours (range, 0.5 to 2.8 ), and 20.7 hours (range,
\end{abstract}

$\mathbf{T}$ AXANES CONSTITUTE a new group of antineoplastic agents with paclitaxel (Fig 1) and docetaxel (Taxotere) as the two main representatives. Paclitaxel is isolated from the bark of the Pacific Yew, Taxus brevifolia. Despite all efforts for synthetic and semisynthetic production, paclitaxel is still only available for commercial use through extraction from bark and needles of the tree. ${ }^{\prime}$

Taxanes act on microtubular structures. Microtubuli are cytoplasmatic cylindric organelles necessary for preservation of cell shape and a variety of cellular processes, including mitosis, cilliary and flagellar motility, and intracellular transport. Microtubuli consist of connected tubulin, which is a heterodimer of two-unidentical monomers, $\alpha$ and $\beta$ tubulin. Paclitaxel binds directly to tubulin, causing massive stable microtubuli. ${ }^{2}$ Cell culture experiments with isolated tumor cells from pleura and peritoneum showed irreversible morphologic changes when treated with $0.1 \mu \mathrm{mol} / \mathrm{L}$ of paclitaxel for 10 minutes. $^{3}$ Purified microtubules assembled in the presence of 10 $\mu \mathrm{mol} / \mathrm{L}$ of paclitaxel for 30 minutes were found to be resistant to depolymerization. ${ }^{4}$ The Michaelis constant $\left(\mathrm{K}_{\mathrm{m}}\right)$ for binding of ${ }^{3} \mathrm{H}$-labeled paclitaxel to microtubule protein in vitro was 0.8 to $2.0 \mu \mathrm{mol} / \mathrm{L}^{2}$

In preclinical studies, paclitaxel showed activity against both solid and leukemia cell lines. It had its greatest activity against intraperitoneal (IP)-implanted B16 murine
4 to 65 ), respectively. Eleven possible metabolites were found, of which three were identified as taxanes by online HPLC-photodiode array (PDA) detection. Investigation of pharmacodynamics shows no clear relationship between the pharmacokinetic parameters area under the plasma concentration time curve (AUC), area under the plasma concentration moment curve (AUMC), maximal plasma concentration $\left(C_{\max }\right)$, clearance, and toxicity. However, a relationship was found between the duration of plasma concentrations above a threshold of $0.1 \mu \mathrm{mol} /$ $L$ with absolute neutrophil count (ANC) and white blood cell count (WBC).

Conclusion: Paclitaxel is metabolized, and putative metabolic products can be found in plasma of patients treated with the drug. Our results indicate that myelosuppression can be predicted by the measurement of the duration of plasma concentrations above the threshold of $0.1 \mu \mathrm{mol} / \mathrm{L}$.

$J$ Clin Oncol 11:2127-2135. (C) 1993 by American Society of Clinical Oncology.

melanoma and the subrenal capsule-implanted MX-1 human breast cancer xenograft in nude mice. Less activity was seen in the IP P388 and L1210 murine leukemias and the subrenal capsule CX-1 colon cancer and LX-1 lung cancer xenografts. ${ }^{5}$

In clinical studies, paclitaxel has been evaluated in leukemia, melanoma, renal cell carcinoma, non-small-cell lung cancer, prostate carcinoma, breast carcinoma, and ovarian carcinoma. ${ }^{6-16}$ Paclitaxel has been most extensively investigated in ovarian cancer. The first phase II study showed that patients who were heavily pretreated with platinum analogs responded even when they proved to be cisplatin-resistant. ${ }^{10}$

Several pharmacokinetic studies, as part of the phase I evaluation, have been published. In all studies, the phar-

From the Department of Medical Oncology, Antoni van Leeuwenhoek Hospital/Netherlands Cancer Institute, Amsterdam; Department of Pharmacy, Slotervaart Hospital, Amsterdam, the Netherlands; and Department of Metabolism and Pharmacokinetics, Bristol-Myers Squibb Co, Syracuse, $N Y$.

Submitted May 12, 1993; accepted July 20, 1993.

Address reprint requests to Manon T. Huizing, MD, Departments of Medical Oncology and Pharmacy, Louwesweg 6, 1066 EC Amsterdam, the Netherlands.

(C) 1993 by American Society of Clinical Oncology.

0732-183X/93/1111-0010\$3.00/0 


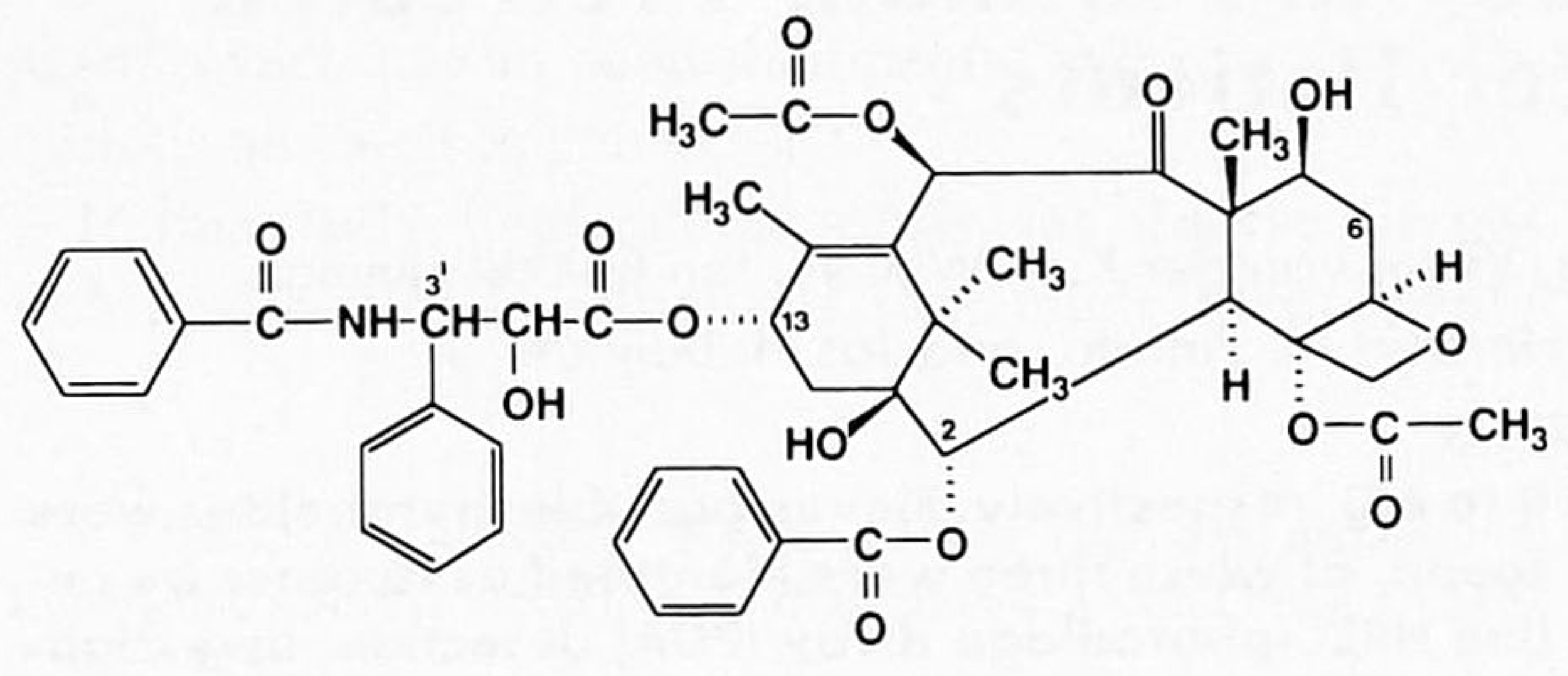

Fig 1. Chemical structure of paclitaxel.

macokinetics were modeled by two-compartment equations. ${ }^{3,14-20}$ Liver metabolism, protein binding, and tissue distribution were suggested to play an important role in plasma disappearance of paclitaxel; only $5 \%$ to $10 \%$ of unchanged paclitaxel is excreted by the kidneys. ${ }^{21}$

Monsarrat et $\mathrm{al}^{22,23}$ found nine metabolites in rat bile with high-performance liquid chromatographic (HPLC) analysis. Three major compounds have been isolated and structurally characterized. One metabolite appeared to be Baccatin III, which has no antitumor activity. Two other major metabolites were active in preventing microtubule disassembly, but were 10 to 41 times less active in inhibition of cell growth of L1210 leukemia cell line. Despite evidence for metabolism, no metabolites were found in human plasma with the currently available HPLC techniques, ${ }^{20}$ with the exception of a single peak detected in human plasma and urine of only one patient. ${ }^{24}$

In this study, we used a new sensitive, selective, and validated HPLC technique combined with a solid-phase extraction as sample pretreatment (Schenkenberger TA, et al, submitted). With this assay, we were able to quantitate paclitaxel concentrations in the low nanomolar region and to detect putative metabolites. This is the first report in the literature whereby metabolic products of paclitaxel were systematically detected in human plasma. The purposes of this study were to investigate the pharmacokinetics and pharmacodynamics of paclitaxel within the international multicenter four-arm trial comparing 175 versus $135 \mathrm{mg} / \mathrm{m}^{2}$ administered as a 3- or 24-hour infusion in platinum-pretreated ovarian carcinoma, and to extend the insight into the metabolic fate of the drug.

\section{PATIENTS AND METHODS}

\section{Patient Selection}

Patients included in this study were treated with paclitaxel at a dose of $175 \mathrm{mg} / \mathrm{m}^{2}$ or $135 \mathrm{mg} / \mathrm{m}^{2}$ on a 3- or 24-hour infusion schedule at the Antoni van Leeuwenhoek Hospital, Amsterdam, the Netherlands. All patients had histologically proven ovarian carcinoma and had been previously treated with platinum.

Eligibility criteria included the following: (1) age between 18 to 75 years; (2) an Eastern Cooperative Oncology Group (ECOG) perfor- mance status $\leq 2$; (3) life expectancy of at least 12 weeks; (4) no prior chemotherapy in the 4 weeks preceding study entry (or 6 weeks for mitomycin, high-dose carboplatin, or nitrosoureas pretreatment); (5) nonpregnant, nonlactating female patients; (6) adequate hematopoetic (absolute neutrophil count [ANC] $\geq 2,000 / \mu \mathrm{L}$ and platelet count $\geq 100,000 / \mu \mathrm{L}$ ), hepatic (total bilirubin $\leq 1.25$ times upper limit), and renal (creatinine 1.5 times upper limit) functions; (7) previous treatment with platinum-containing regimens; (8) no other coexisting medical problems of sufficient severity to prevent full compliance with the study; and (9) patient provision of informed written consent according to institutional guidelines before treatment.

\section{Drug Administration}

Paclitaxel (Taxol; Bristol Myers Squibb; Syracuse, NY) for clinical use is provided as a concentrated sterile solution with $6 \mathrm{mg} / \mathrm{mL}$ in a 5 -mL vial in polyoxyethylated castor oil (Cremophor EL) and dehydrated alcohol (1:1 vol/vol). This was diluted before use with $0.9 \%$ sodium chloride or $5 \%$ dextrose solution. The paclitaxel concentration in this solution did not exceed $0.6 \mathrm{mg} / \mathrm{mL}$. The drug was administered as a continuous intravenous (IV) infusion over 3 or 24 hours in 1,000 $\mathrm{mL}$ of $0.9 \%$ sodium chloride or $5 \%$ dextrose. Cremophor EL may leach plasticizers from solution bags containing polyvinyl chloride; therefore, drug solutions were administered through an IVAC IV administration set with low sorbing tubing (IVAC Corp, San Diego, CA). An IVEX-2 vented filterset $(0.22 \mu \mathrm{m}$; Millipore, Malsheim, France) was inserted into the infusion line.

Patients were pretreated with $40 \mathrm{mg}$ of dexamethasone orally 6 and 12 hours before infusion, clemastine $2 \mathrm{mg} \mathrm{IV}$, and ranitidine 50 mg IV 30 minutes before paclitaxel infusion.

Plasma samples were collected by IV sampling from the arm opposite to the one receiving the infusion. This was performed in the 3-hour infusion scheme before start, 1.5 hours after start, at the end of the infusion, and at 6, 18, 30, 60 minutes, and 2, 4, 8, 12, 24, 30, and 48 hours after the end of the infusion. With the 24-hour infusion, the sampling was performed before start, at 3, 10, 20 hours after the start, at the end of the infusion, and at 6, 18, 30, 60 minutes, and 2, $4,8,12,21,30$, and 48 hours after the end of infusion.

\section{Chemicals}

Paclitaxel (Lot FB 10110; purity, 98.1\%) reference for HPLC analysis and the pharmaceutic formulation (Taxol) were obtained from Bristol Myers Squibb. Acetonitrile and methanol were obtained from ChromAR (Bergen op Zoom, the Netherlands). Ethanol, ammonium acetate, glacial acetic acid, $n$-hexane, and triethylamine were obtained from Merck (Darmstadt, Germany).

\section{Instrumentation}

The HPLC system consisted of a Model 510 pump (Waters Associates, Milford, MA), and an SP 8875 autosampler (Spectra Physics, Santa Clara, CA) with an injection volume of $50 \mu \mathrm{L}$. An APEX octyl analytic HPLC column $(4.6 \times 150 \mathrm{~mm}$; particle size, $5 \mu \mathrm{m})$ (Jones Chromatography, Lakewood, $\mathrm{CO}$ ) was used, which was protected with a precolumn $(4 \times 4 \mathrm{~mm}$; particle size, $5 \mu \mathrm{m})$ packed with LiChrospher RP-8 material (Merck). The mobile phase consisted of acetonitrile-methanol-0.02 $\mathrm{mol} / \mathrm{L}$ ammonium acetate buffer, $\mathrm{pH} 5.0$ $(4: 1: 5 \mathrm{vol} / \mathrm{vol} / \mathrm{vol})$. Detection was performed with an SP $200 \mathrm{UV}$ detector (Spectra Physics) operating at $227 \mathrm{~nm}$. UV-spectra of paclitaxel and the putative metabolites were recorded on-line by using a 1,000-S UV-photodiode array (PDA) detector (Kratos, Ramsey, 
NJ). An SP 4290 integrator coupled to a WINner data system (Spectra Physics) was used for data processing.

\section{Sample Preparation}

Paclitaxel stock solutions were made by dissolving $10 \mathrm{mg}$ of paclitaxel reference material in $2 \mathrm{~mL}$ of ethanol. From these stock solutions, several dilutions were made with a mixture of acetonitrilemethanol-distilled water $(4: 5: 1 \mathrm{vol} / \mathrm{vol} / \mathrm{vol})(A M W)$ to concentrations ranging from 25 to $25,000 \mathrm{ng} / \mathrm{mL}(0.03$ to $29.3 \mu \mathrm{mol} / \mathrm{L})$. The paclitaxel stock solution was stored at $-20^{\circ} \mathrm{C}$. Every 3 months, a fresh stock solution was made. Standard plasma-paclitaxel reference samples for HPLC analysis and calibration were made using blank human edathamil (EDTA) plasma originating from the Central Laboratory of the Netherlands Red Cross Blood Transfusion Service (Amsterdam, the Netherlands). Before use, donor plasma was centrifuged for 10 minutes at $3,000 \mathrm{rpm}$ and $1 \mathrm{~mL}$ of $0.2-\mathrm{mol} / \mathrm{L}$ ammonium acetate buffer solution was added to $1 \mathrm{~mL}$ of spiked plasma. Cyano Bond Elut columns ( $1 \mathrm{~mL}$; Betron Scientific, Rotterdam, the Netherlands) were first conditioned with consecutive washings with $2 \mathrm{~mL}$ of methanol and $0.01 \mathrm{~mol} / \mathrm{L}$ of ammonium acetate buffer, $\mathrm{pH} 5.0$. Next, 1 $\mathrm{mL}$ of diluted plasma/buffer mixture was applied to the columns. The columns were then washed with $2 \mathrm{~mL}$ of $0.01-\mathrm{mol} / \mathrm{L}$ ammonium acetate, $\mathrm{pH} 5.0,2 \mathrm{~mL}$ of methanol-0.01-mol/L ammonium acetate, $\mathrm{pH} 5.0(2: 8 \mathrm{vol} / \mathrm{vol})$, and $1 \mathrm{~mL}$ of hexane. The columns were dried under vacuum for 1 minute. The analytes were eluted from the columns with $2 \mathrm{~mL}$ of a mixture of acetonitrile-triethylamine (1,000:1 $\mathrm{vol} / \mathrm{vol}$ ), in 2.0-mL Eppendorf Safe-Lock tubes 3816 (Merck). The eluent was evaporated to dryness under a nitrogen stream at $30^{\circ} \mathrm{C}$. Samples were reconstituted with AMW by vortex mixing for 1 minute. Patients' whole blood samples $(5 \mathrm{~mL})$ were obtained in EDTA tubes before and after paclitaxel administration, and serially following the completion of the infusion. All samples were immediately centrifuged (3,000 rpm for 10 minutes) and plasma was frozen at $-20^{\circ} \mathrm{C}$ and assayed within 4 weeks. The same solid-phase extraction procedure was followed for patient samples and calibration samples.

\section{Calibration and Quantitation}

Standard samples were prepared by making the appropriate dilutions of paclitaxel in blank, drug-free plasma. These samples were analyzed with each run for the construction of a calibration curve. The calibration curves were calculated by weighted $(1 / x)$ linear regression analysis.

The calibration samples for paclitaxel in plasma ranged from 0.012 $\mu \mathrm{mol} / \mathrm{L}$ to $12 \mu \mathrm{mol} / \mathrm{L}$. Paclitaxel concentrations in patients' samples were calculated by comparison of peak areas with those obtained from the calibration samples. The concentrations of the metabolites were estimated by using paclitaxel as reference standard and the results should, therefore, be considered as paclitaxel equivalents, assuming that the recoveries and molar absorbtivities at $227 \mathrm{~nm}$ of the metabolites are similar to paclitaxel.

\section{Validation}

A full validation was completed for human plasma of this analytic procedure. The within-day and between-day precision and the accuracy were determined in three separate validation runs. The paclitaxel extraction efficiency was determined by comparing the slopes of human plasma calibration curves to standard curves prepared in AMW. For each standard curve, seven standard plasma samples were taken in duplicate in the concentrations $0.012,0.059,0.12,0.59,1.2$,
5.9 , and $12 \mu \mathrm{mol} / \mathrm{L}$ ( 10 to $10,000 \mathrm{ng} / \mathrm{mL}$ ). For the accuracy and precision determinations, five additional samples were taken with concentrations of $0.059,0.59$, and $5.9 \mu \mathrm{mol} / \mathrm{L}$ ( 50 to $5,000 \mathrm{ng} / \mathrm{mL}$ ).

\section{Pharmacokinetic Analysis}

The plasma disappearance curves were modeled by using the Kinfit computer program (MW $\backslash$ Pharm, Medi $\backslash$ ware BV, Groningen, the Netherlands). ${ }^{25}$ This nonlinear, least-squares, iterative regression program determines slopes and intercepts of the logarithmically plotted curves of multiexponential functions and provides a correlation coefficient of the fitted curve.

The postinfusion paclitaxel kinetics could be described best by the use of a triexponential model $(n=3)$, with the time-concentration function:

$$
C_{t}=\sum_{i=1}^{N}\left\{C_{i} \times e^{(-\lambda i \times t)}\right\}
$$

where $\lambda_{i}$ is the exponent of the $i-$ th exponential term, and $C_{i}$ is the initial concentration of the $\mathrm{i}$-th component of the curve. Curve fitting with this model yields the parameters $C_{1}, C_{2}, C_{3}, \lambda_{1}, \lambda_{2}$, and $\lambda_{3}$. The half-lives $\left(\mathrm{t}_{1 / 2} \mathrm{~s}\right)$ are calculated from the equations $\mathrm{t}_{1 / 2}(\alpha)=0.693 / \lambda_{1}$, $t_{1 / 2}(\beta)=0.693 / \lambda_{2}$, and $t_{1 / 2}(\gamma)=0.693 / \lambda_{3}$. Other pharmacokinetic parameters were calculated by a noncompartmental analysis. The total area under the curve $\left(\mathrm{AUC}_{0 \rightarrow \infty}\right)$ was calculated using the linear trapezoidal method with extrapolation of the terminal phase to infinity $\left(\mathrm{C}_{\text {last }} / \lambda_{3}\right)$, where $\mathrm{C}_{\text {last }}$ is the last measured concentration. The area under the moment curve $\left(\mathrm{AUMC}_{0 \rightarrow \infty}\right)$ was also calculated by the trapezoidal rule with extrapolation to infinity $\left(\left[\mathrm{C}_{\text {last }} \times \mathrm{t}_{\text {last }}\right] / \lambda_{3}+\mathrm{C}_{\text {last }} /\right.$ $\lambda_{3}{ }^{2}$ ), with $t_{\text {last }}$ as the last measured time point with $C_{\text {last }}$. The mean residence time (MRT) was calculated by dividing the AUC by the AUMC.

Total-body clearance $\left(\mathrm{CL}_{\mathrm{T}}\right)$ was calculated by dividing the dose $\left(D_{\text {iv }}\right)$ by the $\mathrm{AUC}_{0 \rightarrow \infty}$. Volume at steady-state $\left(\mathrm{V}_{\mathrm{ss}}\right)$ was calculated with the following equation ${ }^{26}$ :

$$
\mathrm{V}_{\mathrm{ss}}=\frac{\mathrm{D}_{\mathrm{iv}} \cdot \mathrm{AUMC}}{\mathrm{AUC}}-\frac{\mathrm{D}_{\mathrm{iv}} \cdot \mathrm{T}}{2 \cdot \mathrm{AUC}}
$$

where $\mathrm{T}$ is the infusion time. The peak plasma concentrations $\left(\mathrm{C}_{\max }\right)$ are observed measured values. The AUCs of the metabolic products were determined using the trapezoidal rule without extrapolation to infinity.

\section{Pharmacodynamic Analysis}

The hematologic toxicity was evaluated as percentage decrease (\%D) in granulocyte or WBC count using the following equation:

$$
\% \mathrm{D}=\frac{\text { Pretreatment ANC }(\mathrm{WBC})-\mathrm{Nadir} \text { ANC }(\mathrm{WBC})}{\text { Pretreatment ANC }(\mathrm{WBC})} \cdot 100 \% .
$$

The relationships were modeled with the sigmoidal maximum effect $\left(\mathrm{E}_{\max }\right)$ equation:

$$
E(\% \text { change })=\frac{E_{\max } \cdot P^{H}}{P_{50}^{H}+P^{H}},
$$

where $E_{\max }$ represents the maximal elicitable effect, and $P$ represents the pharmacokinetic parameter. $\mathrm{P}_{50}$ is the value of the parameter by which $50 \%$ of $\mathrm{E}_{\max }$ is elicited. The computer program NCSS (Dr Jerry L. Hintze, East Kaysville, UT) was used to estimate the exponent $\mathrm{H}$, also known as the Hill constant, which determines the shape of the curve, and $\mathrm{P}_{50}$. 
Table 1. Patient Characteristics $(N=18)$

\begin{tabular}{lcc}
\hline & Median & Range \\
\hline Median age, years & 56 & $34-73$ \\
Performance status (ECOG) & 8 & \\
0 & 10 & \\
1 & & \\
No. of prior chemotherapeutic treatment & & \\
$\quad$ regimens & 12 & \\
1 & 6 & \\
2 & 6 & \\
Platinum-sensitive disease & 12 & \\
Platinum-resistant disease & 15 & \\
Extraabdominal or liver disease & 1 & \\
Prior radiation therapy &
\end{tabular}

\section{RESULTS}

A total of 18 patients were entered onto the pharmacokinetic part of the trial. Patient characteristics are listed in Table 1. All patients had ovarian cancer and were pretreated with platinum-containing chemotherapy before protocol entry. Approximately $40 \%$ of patients were refractory to platinum treatment (seven patients relapsed within 180 days after the last platinum treatment).

All patients were considered to be assessable for toxicity and response, with the exception of one patient who had no measurable disease. The median number of prior regimens per patient was two (range, one to three). The median age of the population was 56 years (range, 34 to 73 ), with a median ECOG performance status of 1 (range, 0 to 1). A total of 180 courses of paclitaxel therapy were administered to the patients who participated in this trial. The median number of courses per patient was 10 (range, two to 18). Reasons for the discontinuation of therapy included disease progression, completion of therapy, patient wish, and neurotoxicity in one patient.

\section{Toxicity}

Table 2 lists the hematologic toxicity observed after the courses with pharmacokinetic monitoring in the four different treatment arms. Bone marrow suppression was generally mild in the 3-hour infusion arm, but more severe and common in the 24-hour arm. At the $175-\mathrm{mg} / \mathrm{m}^{2}$ dose level, the majority of patients experienced WBC count decreases to less than $2,000 / \mu \mathrm{L}$. Generally, the WBC count nadir resolved within 1 week. It lasted longer than 7 days in only five patients. In four patients, no exact analysis could be performed, because no laboratory values were available. Two patients experienced fever, probably due to severe neutropenia. Nearly all patients developed mild rashes (flushing of the cheek). Hypersensitivity reactions and cardiac complications were not observed. Mild neuropathy was noted in two patients. In one patient, neuropathy was the reason for stopping therapy. All patients experienced alopecia grade II to III. Two patients experienced mild mucositis. Myelosuppression was noncumulative and reversible.

\section{Chromatography}

The retention time of paclitaxel in the presented HPLC system was 10 minutes (range, 9.84 to 10.11 ). Figure $2 \mathrm{~B}$ shows a chromatogram of a plasma sample at the end of infusion of a patient treated with paclitaxel $\left(175 \mathrm{mg} / \mathrm{m}^{2}\right.$ as a 3-hour infusion). Putative metabolites were named in the order of their appearance in the chromatograms: metabolite I at 3.9 to 4.1 , metabolite II at 5.2, metabolite III at 5.6, metabolite IV at 6.3, metabolite $\mathrm{V}$ at 7.2, metabolite VI at 7.7, metabolite VII at 8.4, metabolite VIII at 13.6, metabolite IX at 16.1, metabolite $X$ at 31.5, and metabolite XI at 38.2 minutes. The pattern of existing metabolites differs strongly per patient. On-line PDA detection showed that peaks I, II, and V possess similar UV characteristics as the parent paclitaxel, indicating that the taxane chromophor is still intact in these products (Fig 3 ). The amounts of the other eight metabolites were too small to allow further analysis at this stage.

\section{Validation}

The limit of detection in plasma is $0.007 \mu \mathrm{mol} / \mathrm{L}$ (signalto-noise ratio, $3: 1)$ using only a $0.5-\mathrm{mL}$ sample. The assay is linear over a concentration range of 0.012 to $12 \mu \mathrm{mol} /$ $\mathrm{L}$ in human plasma with a correlation coefficient $R^{2}>$

Table 2. Patient Events Stratified by Paclitaxel Treatment Arm

\begin{tabular}{|c|c|c|c|c|}
\hline \multirow[b]{2}{*}{ Patient Categories } & \multicolumn{4}{|c|}{ No. of Patients in Each Treatment Arm } \\
\hline & $\begin{array}{c}135 \mathrm{mg} / \mathrm{m}^{2} \text { Over } \\
3 \text { Hours }\end{array}$ & $\begin{array}{c}175 \mathrm{mg} / \mathrm{m}^{2} \text { Over } \\
3 \text { Hours }\end{array}$ & $\begin{array}{c}135 \mathrm{mg} / \mathrm{m}^{2} \text { Over } \\
24 \text { Hours }\end{array}$ & $\begin{array}{c}175 \mathrm{mg} / \mathrm{m}^{2} \text { Over } \\
24 \text { Hours }\end{array}$ \\
\hline Total no. of patients treated & 7 & 5 & 2 & 4 \\
\hline Mean no. of cycles & 11 & 10 & 10 & 7 \\
\hline Patients with granulocytopenia $\geq$ grade 3 & 3 & 3 & 2 & 4 \\
\hline Patients with thrombocytopenia $\geq$ grade 3 & 0 & 1 & 0 & 0 \\
\hline Mean nadir ANC $(\mu \mathrm{L})$ & 1,464 & 1,026 & 360 & 272 \\
\hline
\end{tabular}



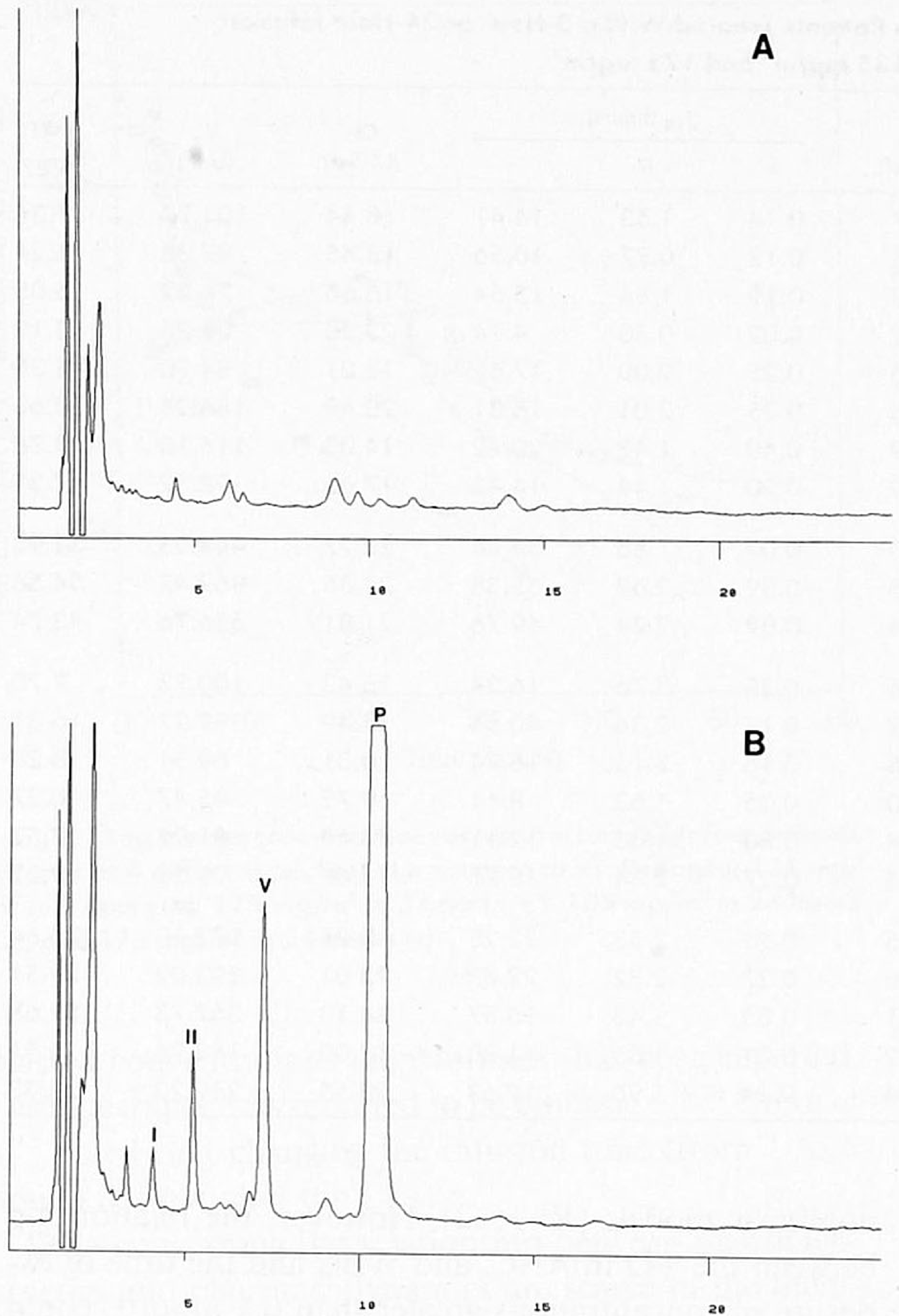

Fig 2. Chromatogram of (A) a blank plasma sample, and (B) a plasma sample from a patient at the end of infusion $\left(175 \mathrm{mg} / \mathrm{m}^{2}\right.$, 3hour infusion). Peak $P$ is paclitaxel; I, II, and V are metabolites.

0.999. The accuracy and precision (within- and betweenday) are listed in Table 3. The precisions are obtained by one-way analysis of variance (ANOVA) for each concentration. The extraction efficiency was $92 \%$ for human plasma $(n=3)$.

\section{Pharmacokinetic Analysis}

The pharmacokinetic parameters of paclitaxel in 18 patients treated in the four different treatment arms (high dose $\left[175 \mathrm{mg} / \mathrm{m}^{2}\right] v$ low dose $\left[135 \mathrm{mg} / \mathrm{m}^{2}\right]$ and short $(3$ hours) versus long [24 hours] infusion) are listed in Table 4. The $\mathrm{C}_{\max }$ values were significantly correlated with dose $(P=.0001)$ and infusion duration $(P=.0012)$. Mean $\mathrm{C}_{\max }$ values in the 24-hour infusion arm were approximately $10 \%$ of the $\mathrm{C}_{\max }$ reached in the 3 -hour infusion regimen.

Average $C_{\max }$ values were $0.23 \pm 0.03 \mu \mathrm{mol} / \mathrm{L}$ (range, 0.2 to 0.25 ) at $135 \mathrm{mg} / \mathrm{m}^{2}$ and $0.43 \pm 0.14 \mu \mathrm{mol} / \mathrm{L}$ (range,

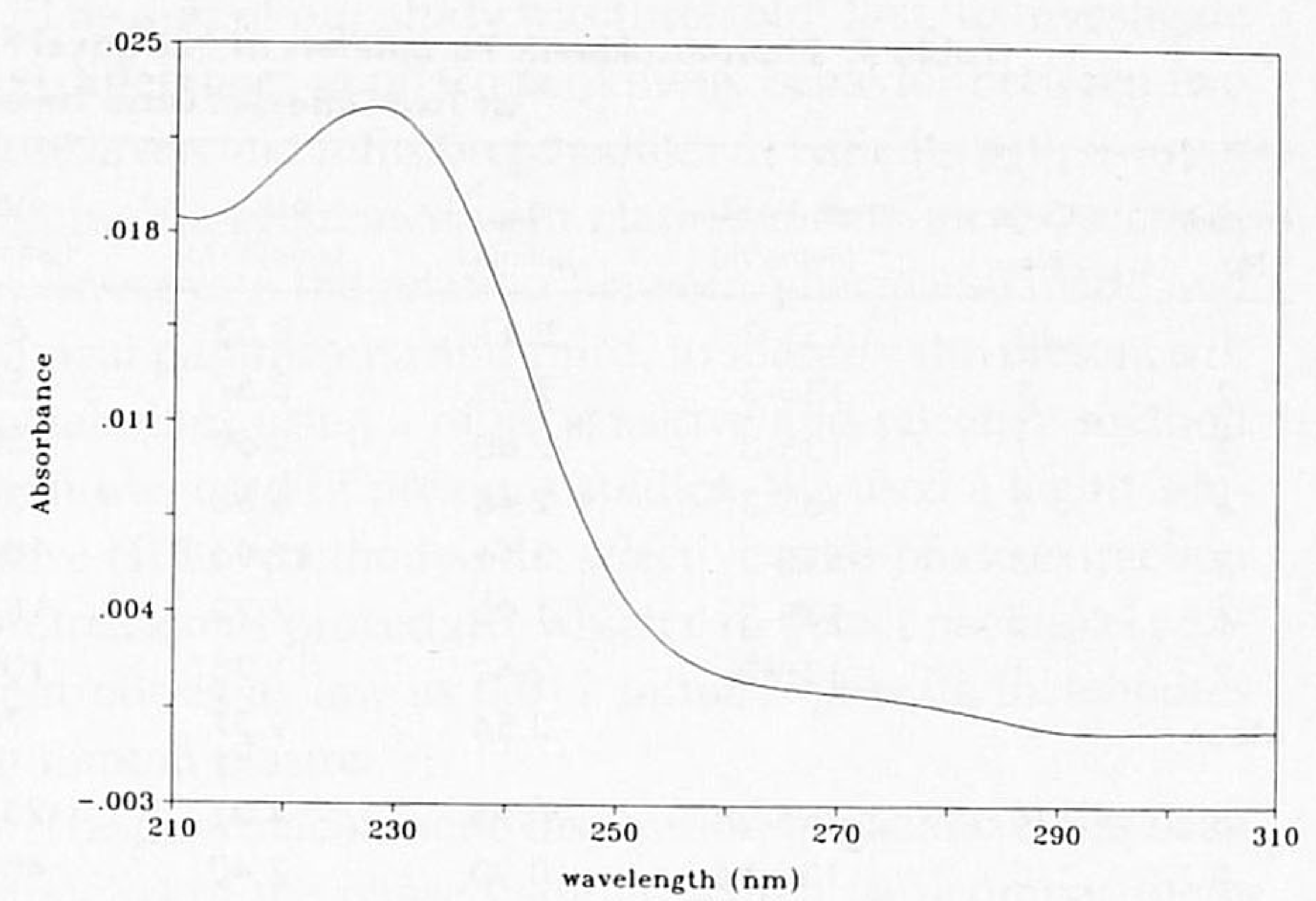

Fig 3. UV-PDA spectrum of $V$. The spectra of paclitaxel and metabolites I and II are similar.

0.31 to 0.61 ) at $175 \mathrm{mg} / \mathrm{m}^{2}$ for the 24-hour arms, with $2.54 \pm 0.52 \mu \mathrm{mol} / \mathrm{L}$ (range, 1.9 to 3.51 ) at $135 \mathrm{mg} / \mathrm{m}^{2}$ and $4.27 \pm 1.26 \mu \mathrm{mol} / \mathrm{L}$ (range, 2.8 to 5.92 ) at $175 \mathrm{mg} /$ $\mathrm{m}^{2}$ for the 3-hour infusion arm.

Plasma disappearance curves (Fig 4) appeared to be triphasic, with mean $\mathrm{t}_{1 / 2} \mathrm{~S}$ for the $\alpha, \beta$, and $\gamma$ phases (average of all arms) of $0.19 \pm 0.11$ hours (range, 0.01 to 0.4 ), $1.89 \pm 0.67$ hours (range, 0.5 to 3.15 ), and $20.71 \pm$ 14.23 hours (range, 4.14 to 65.38 ), respectively. Although there is a great interpatient variation with only limited patient numbers, results from the patients who received $135 \mathrm{mg} / \mathrm{m}^{2}$ over 3 or 24 hours suggest that the $t_{1 / 2}(\gamma)$ is longer when paclitaxel is administered over a prolonged period of time at this dose level $\left(\mathrm{t}_{1 / 2}(\gamma)=14.43 \pm 5.53\right.$ hours $v 49.76 \pm 22.09$ hours, respectively). For doses in the $1: 1.30$ proportion $\left(135 \mathrm{mg} / \mathrm{m}^{2}: 175 \mathrm{mg} / \mathrm{m}^{2}\right)$, mean $\mathrm{AUC}_{0 \rightarrow \infty}$ values increased in the $1: 1.89$ proportion (mean $\mathrm{AUC}_{0 \rightarrow \infty} 9.37 \mu \mathrm{mol} / \mathrm{L} \cdot \mathrm{h}: 16.81 \mu \mathrm{mol} / \mathrm{L} \cdot \mathrm{h}$ ) for the 3-hour infusion group, and 1:1.27 proportion (mean $\mathrm{AUC}_{0 \rightarrow \infty}$ $7.31 \mu \mathrm{mol} / \mathrm{L} \cdot \mathrm{h}: 9.30 \mu \mathrm{mol} / \mathrm{L} \cdot \mathrm{h}$ ) for the 24 -hour infusion group. The mean $\mathrm{CL}_{\mathrm{T}}$ is $15.59 \pm 4.11 \mathrm{~L} / \mathrm{h} / \mathrm{m}^{2}$ (range, 9.72 to 23.28 ) for the 3 -hour infusion and $22.97 \pm 5.86 \mathrm{~L} / \mathrm{h} /$ $\mathrm{m}^{2}$ (range, 17.00 to 34.13 ) for the 24-hour infusion. It was significantly $(P=.0083)$ correlated with infusion time. A significant infusion-dose correlation was found for $\mathrm{V}_{\mathrm{ss}}$. Mean $\mathrm{V}_{\mathrm{ss}}$ was significantly $(P=.0006)$ larger when pac-

Table 3. HPLC Validation Characteristics ( $n=17$ )

\begin{tabular}{lccc}
\hline $\begin{array}{c}\text { Concentration } \\
(\mu \mathrm{mol} / \mathrm{L})\end{array}$ & $\begin{array}{c}\text { Accuracy } \\
(\%)\end{array}$ & $\begin{array}{c}\text { Between-Day } \\
\text { Precision (\%) }\end{array}$ & $\begin{array}{c}\text { Within-Day } \\
\text { Precision (\%) }\end{array}$ \\
\hline 0.059 & -6.0 & 10.9 & 3.4 \\
0.59 & +0.2 & 3.4 & 1.7 \\
5.9 & +1.9 & 1.0 & 1.1 \\
\hline
\end{tabular}


Table 4. Pharmacokinetic Parameters of Paclitaxel From Patients Treated With a 3-Hour or 24-Hour Infusion at Two Different Dose Levels: $135 \mathrm{mg} / \mathrm{m}^{2}$ and $175 \mathrm{mg} / \mathrm{m}^{2}$

\begin{tabular}{|c|c|c|c|c|c|c|c|c|c|c|c|}
\hline \multirow{2}{*}{$\begin{array}{l}\text { Patient } \\
\text { No. }\end{array}$} & \multirow{2}{*}{$\begin{array}{l}\text { Cycle } \\
\text { No. }\end{array}$} & \multirow{2}{*}{$\begin{array}{l}\text { Dose-infusion } \\
\left(\mathrm{mg} / \mathrm{m}^{2} / \mathrm{h}\right)\end{array}$} & \multirow{2}{*}{$\begin{array}{c}\mathrm{C}_{\max } \\
(\mu \mathrm{mol} / \mathrm{L})\end{array}$} & \multirow{2}{*}{$\begin{array}{c}\mathrm{AUC}_{\infty} \\
(\mu \mathrm{mol} / \mathrm{L} \cdot \mathrm{h})\end{array}$} & \multirow{2}{*}{$\begin{array}{c}\mathrm{AUMC}_{\infty} \\
\left(\mu \mathrm{mol} / \mathrm{L} \cdot \mathrm{h}^{2}\right)\end{array}$} & \multicolumn{3}{|c|}{$t_{1 / 2}$ (hours) } & \multirow{2}{*}{$\begin{array}{c}\mathrm{Cl}_{T} \\
\left(\mathrm{~L} / \mathrm{h} / \mathrm{m}^{2}\right)\end{array}$} & \multirow{2}{*}{$\begin{array}{c}V_{31} \\
\left(L / m^{2}\right)\end{array}$} & \multirow{2}{*}{$\begin{array}{l}\text { MRT } \\
\text { (hours) }\end{array}$} \\
\hline & & & & & & $\alpha$ & $\beta$ & $\gamma$ & & & \\
\hline 1 & 12 & $135-3$ & 2.11 & 8.53 & 62.57 & 0.14 & 1.53 & 14.41 & 18.44 & 101.23 & 7.34 \\
\hline 2 & 7 & $135-3$ & 2.36 & 8.57 & 53.45 & 0.12 & 0.77 & 10.56 & 18.45 & 87.38 & 6.24 \\
\hline 3 & 1 & $135-3$ & 2.80 & 9.69 & 58.62 & 0.19 & 1.84 & 15.54 & 16.66 & 74.82 & 6.05 \\
\hline 4 & 2 & $135-3$ & 2.48 & 6.86 & 21.92 & 0.02 & 0.50 & 4.14 & 23.28 & 38.26 & 3.19 \\
\hline 5 & 3 & $135-3$ & 3.51 & 12.96 & 108.65 & 0.25 & 2.00 & 17.61 & 12.21 & 84.20 & 8.39 \\
\hline 6 & 3 & $135-3$ & 1.90 & 7.72 & 81.85 & 0.25 & 2.01 & 18.31 & 20.49 & 186.24 & 10.60 \\
\hline 7 & 1 & $135-3$ & 2.62 & 11.25 & 109.89 & 0.40 & 1.42 & 20.42 & 14.08 & 116.10 & 9.76 \\
\hline Mean & & & 2.54 & 9.37 & 70.99 & 0.20 & 1.44 & 14.43 & 17.66 & 98.32 & 7.37 \\
\hline 8 & 12 & $135-24$ & 0.25 & 7.21 & 237.53 & 0.09 & 1.86 & 34.14 & 22.27 & 444.05 & 32.93 \\
\hline 9 & 2 & $135-24$ & 0.20 & 7.40 & 403.95 & 0.09 & 2.62 & 65.38 & 21.35 & 869.47 & 54.56 \\
\hline Mean & & & 0.23 & 7.31 & 320.74 & 0.09 & 2.24 & 49.76 & 21.81 & 656.76 & 43.74 \\
\hline 10 & 9 & $175-3$ & 2.80 & 12.53 & 96.46 & 0.38 & 2.76 & 16.24 & 16.43 & 100.73 & 7.70 \\
\hline 11 & 6 & $175-3$ & 3.87 & 15.25 & 248.77 & 0.18 & 2.34 & 40.54 & 13.49 & 199.27 & 16.31 \\
\hline 12 & 1 & $175-3$ & 5.20 & 19.87 & 164.88 & 0.16 & 3.15 & 16.74 & 10.31 & 69.51 & 8.30 \\
\hline 13 & 2 & $175-3$ & 5.92 & 21.08 & 132.20 & 0.35 & 1.63 & 8.11 & 9.72 & 45.47 & 6.27 \\
\hline 14 & 3 & $175-3$ & 3.58 & 15.33 & 115.44 & 0.30 & 1.80 & 12.11 & 13.48 & 81.27 & 7.53 \\
\hline Mean & & & 4.27 & 16.81 & 151.55 & 0.27 & 2.34 & 18.75 & 12.69 & 99.25 & 9.22 \\
\hline 15 & 6 & $175-24$ & 0.47 & 10.13 & 209.05 & 0.22 & 2.53 & 22.28 & 20.06 & 172.10 & 20.64 \\
\hline 16 & 3 & $175-24$ & 0.32 & 8.91 & 262.88 & 0.27 & 2.32 & 27.87 & 23.01 & 393.02 & 29.51 \\
\hline 17 & 1 & $175-24$ & 0.31 & 5.96 & 135.21 & 0.05 & 1.43 & 16.57 & 34.13 & 367.73 & 22.68 \\
\hline 18 & 1 & $175-24$ & 0.61 & 12.20 & 250.22 & 0.01 & 1.55 & 11.80 & 17.00 & 143.94 & 20.51 \\
\hline Mean & & & 0.43 & 9.30 & 214.34 & 0.14 & 1.96 & 19.63 & 23.55 & 269.20 & 23.33 \\
\hline
\end{tabular}

litaxel was administered over 24 hours than during the 3 hour infusion $\left(656.76 \pm 261.12 \mathrm{~L} / \mathrm{m}^{2} v 98.32 \pm 49.21 \mathrm{~L} /\right.$ $\mathrm{m}^{2}$ ) at the $135-\mathrm{mg} / \mathrm{m}^{2}$ dose. It was also found that for the 24-hour infusions, the $135-\mathrm{mg} / \mathrm{m}^{2}$ dose resulted in greater mean $\mathrm{V}_{\mathrm{ss}}$ than in patients who received $175 \mathrm{mg} / \mathrm{m}^{2}(656.76$ $\pm 300.82 \mathrm{~L} / \mathrm{m}^{2} v 269.2 \pm 129.30 \mathrm{~L} / \mathrm{m}^{2}$ ). Major differences were observed for both dose and infusion duration in the four different treatment arms and MRT, with a larger MRT with the drug administered as a 24-hour infusion.

A total of 11 possible metabolites have been identified in 16 of 18 patients. UV-spectrometry of the three major metabolites (I, II, V) substantiated that they were taxanes. A specific taxane spectrum was seen for the three metabolites, with a maximum absorbtion at $227 \mathrm{~nm}$. The amounts of the other eight metabolites were too small to allow further analysis. The number and the total AUC (as paclitaxel equivalents) of these metabolites are significantly greater after 3-hour than after 24-hour infusions.

Other pharmacokinetic parameters of the metabolites cannot be given at this stage of investigation and have to be awaited for the elucidation of these chemical structures.

\section{Pharmacodynamic Analysis}

No relationship for nonhematologic or hematologic toxicity with the AUC could be described by linear or nonlinear models $\left(R^{2}<.2\right)$. However, the relationship between the \%D in ANC, and WBC and the time of exposure of concentrations greater than $0.1 \mu \mathrm{mol} / \mathrm{L}$ could be described adequately by the sigmoidal $\mathrm{E}_{\max }$ model. Figure 5 is a plot of this relationship using data obtained from all patients. With this model, the duration of the plasma concentration above the threshold of $0.1 \mu \mathrm{mol} / \mathrm{L}$ predicted to yield a $50 \%$ decrease in ANC was 11.16 hours and for WBC 15.16 hours. The Hill constant was 2.73 and 2.16 , respectively. No relation could be found between the AUC or AUMC above the concentration threshold of $0.1 \mu \mathrm{mol} / \mathrm{L}$ and any hematologic or nonhematologic parameter. One patient experienced a severe neutropenia (grade IV; duration, 7 days), which did not seem to have a relationship with any pharmacokinetic parameter.

\section{DISCUSSION}

Paclitaxel has been studied extensively both in the laboratory and in the clinic. However, its complete pharmacokinetic profile in humans has not yet been fully understood. Liver metabolism, extensive protein binding, and tissue distribution have been mentioned as playing an important role in the disposition of the drug. Only $5 \%$ to $10 \%$ of unchanged paclitaxel is excreted by the kidneys. $\mathrm{C}_{\max }$ values correlate with dose, and a rapid decline in 


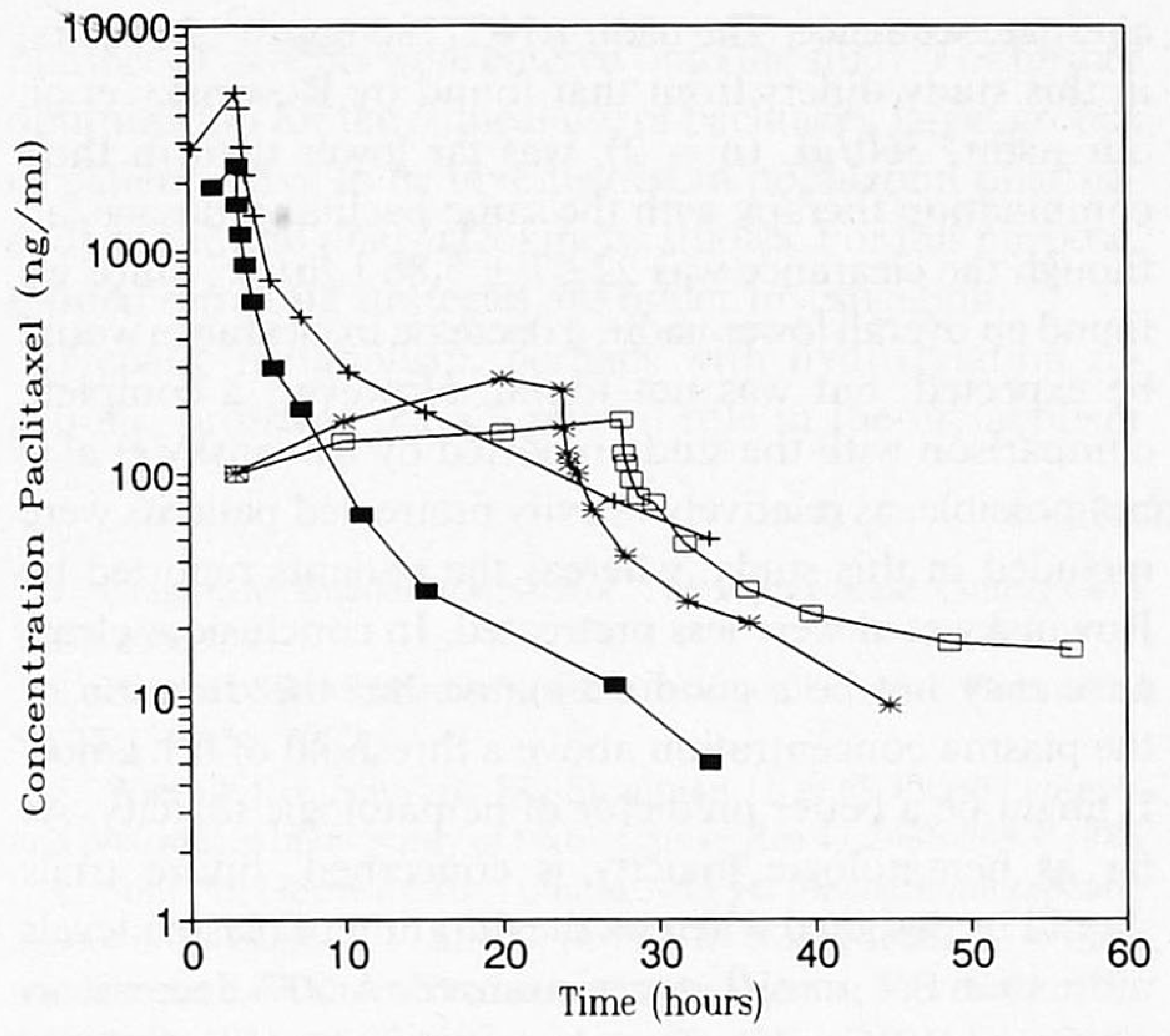

Fig 4. Log plasma concentration versus time curves for four patients treated at 4 different paclitaxel treatment arms. Dosages: $135 \mathrm{mg} /$ $\mathrm{m}^{2}$ in 3 hours $(\square), 175 \mathrm{mg} / \mathrm{m}^{2}$ in 3 hours $(+), 135 \mathrm{mg} / \mathrm{m}^{2}$ in 24 hours (), and $175 \mathrm{mg} / \mathrm{m}^{2}$ in 24 hours (*)

plasma concentrations after infusion has been reported. Disappearance was reported to be biphasic. ${ }^{3,14-20}$ Grem et $\mathrm{al}^{15}$ noted that changing the infusion time (from 1 to 6 hours) did not alter the $\mathrm{CL}_{\mathrm{T}}$.

Data concerning the relationship between pharmacokinetics and pharmacodynamics are scarce in the literature, and have been reported to be as follows: (1) a rough correlation between the nadir WBC, absolute change in $\mathrm{WBC}$, and the $A U C^{18,19} ;(2)$ in a cell culture experiment with isolated tumor cells, cell death occurred after a 10minute incubation with $0.1 \mu \mathrm{mol} / \mathrm{L}$ of paclitaxel ${ }^{3}$; and (3) a decrease in the $\mathrm{CL}_{\mathrm{T}}$ of paclitaxel occurs when cisplatin preceded paclitaxel chemotherapy, resulting in more severe myelotoxicity. ${ }^{16}$ In general, myelotoxicity and neutropenia were found to be the dose-limiting factors in former studies. ${ }^{7,8,14-16,19}$

Metabolites were detected by Monsarrat et $\mathrm{al}^{22,23}$ in human and rat bile. The major metabolites detected in rat bile are hydroxylated products; one had a hydroxyl group on the para-position of the phenyl function at C-3', another at the meta-position of the benzoate group at the C-2 position. Another metabolite was identified as Baccatin III. In human bile, Monsarrat et $\mathrm{al}^{23}$ detected 6-hydroxytaxol and a metabolite with a hydroxyl group at the phenylmoiety at C-3'. In the analytic study reported by Rizzo et al, ${ }^{24}$ one potential metabolite has been detected, but not identified, in human plasma and urine after a liquid-liquid extraction followed by solid-phase extraction.
The aim of our study was threefold: first, to investigate the differences in pharmacokinetic behavior between two dose levels and infusion schedules in patients with ovarian carcinoma pretreated with platinum derivatives; second, to investigate the relation between pharmacokinetic and clinical parameters; and third, to identify the presence of metabolites using a more sensitive and selective method than was used in previous studies. We used a highly sensitive HPLC method and a selective solid-phase extraction pretreatment procedure, which can detect paclitaxel concentrations as low as $0.012 \mu \mathrm{mol} / \mathrm{L}$ plus its metabolites in human plasma.

The pharmacokinetic disposition of paclitaxel has been modeled in the phase I studies with a two-compartment model. However, compartmental, nonlinear, least-squares
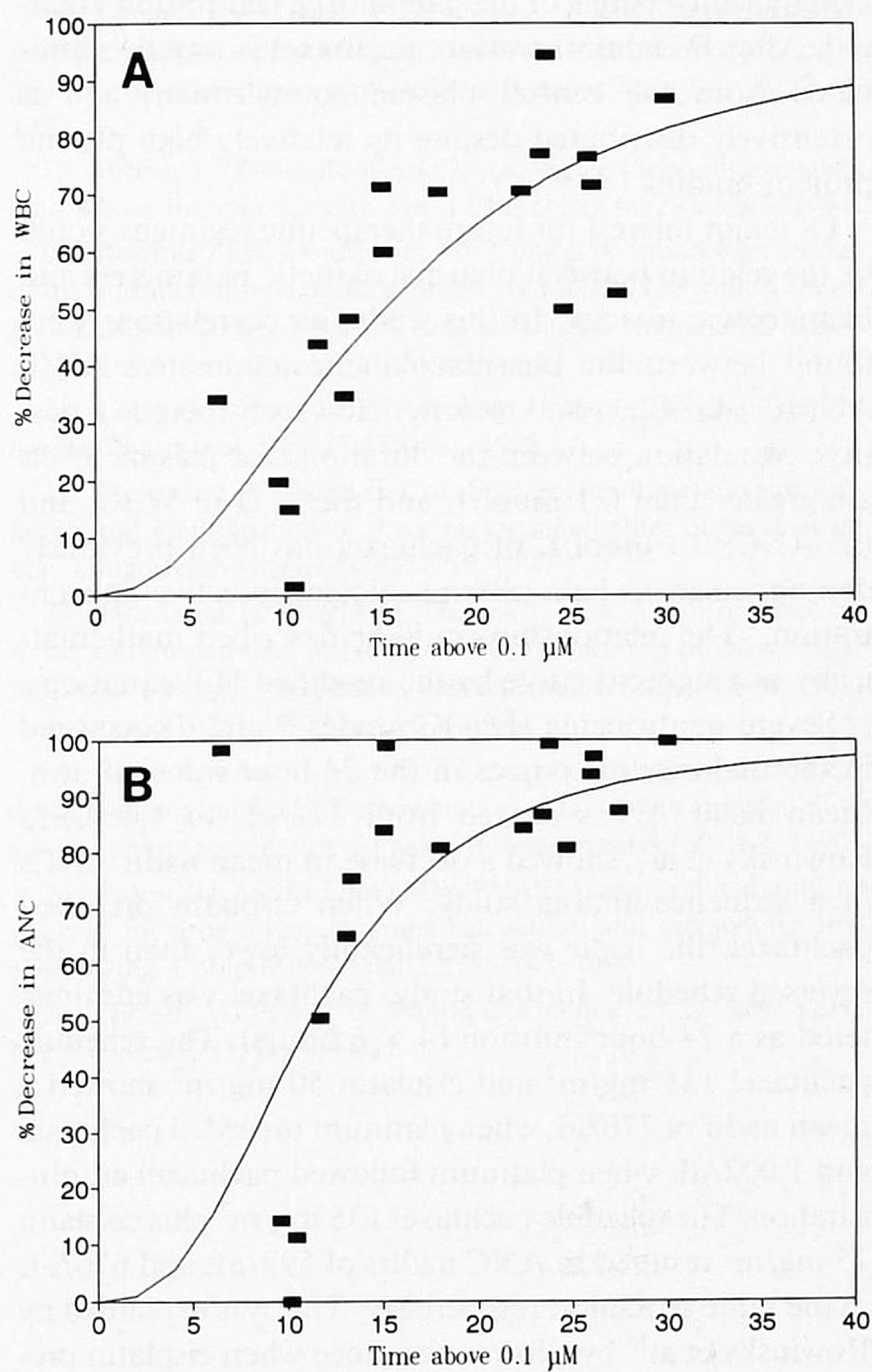

Fig 5. \%D in (A) WBC and (B) ANC versus duration of threshold above $0.1 \mu \mathrm{mol} / \mathrm{L}$. The curve has been fitted to the sigmoidal $\mathrm{E}_{\max }$ model (a, measured values; *- ${ }^{*}$, fitted curve). 
regression analysis in this study showed that a three-compartment model gives a better description. The reason for this discrepancy is probably due to the sensitivity of the HPLC assay allowing us to detect paclitaxel levels as low as $0.012 \mu \mathrm{mol} / \mathrm{L}$ by which an extra disposition phase appeared.

In contrast to Grem et al, ${ }^{15}$ who noted that changing the infusion time (from 1 to 6 hours) did not alter the paclitaxel $\mathrm{CL}_{\mathrm{T}}$, we found that there was a significant difference in $\mathrm{CL}_{\mathrm{T}}$. In our study, there was a significant effect of the infusion time on $\mathrm{CL}_{\mathrm{T}} ; \mathrm{CL}_{\mathrm{T}}$ values after 24-hour infusions were larger than $\mathrm{CL}_{\mathrm{T}}$ values after 3-hour infusions $(P=.0083)$. There also was a clear increase in $\mathrm{C}_{\max }$ by increasing the dose or administering the drug in a shorter period of time. A more than proportional increase for the AUC was observed in the group that received the higher dose. This may indicate a limited capacity for enzymatic conversions of the parent drug (saturation kinetics). After IV administration, paclitaxel is rapidly eliminated from the central plasma compartment and is extensively distributed despite its relatively high plasma protein binding $(\sim 95 \%)$.

Of major interest for future therapeutic regimens would be the relation between pharmacokinetic parameters and hematologic toxicity. In this study, no correlations were found between the pharmacokinetic parameters AUC, AUMC, and $\mathrm{C}_{\max }$, and toxicity. However, there is a positive correlation between the duration that plasma levels are greater than $0.1 \mu \mathrm{mol} / \mathrm{L}$ and the $\% \mathrm{D}$ in $\mathrm{WBC}$, and the ANC; $0.1 \mu \mathrm{mol} / \mathrm{L}$ of paclitaxel has been previously demonstrated to be a pharmacologically active concentration. ${ }^{3}$ The relationship could be described mathematically as a sigmoid curve by the modified Hill equations.

Severe neutropenia (ECOG grades 3 and 4) occurred in the majority of courses in the 24-hour infusion arm. Mean nadir ANCs ranged from $272 / \mu \mathrm{L}$ to $1,464 / \mu \mathrm{L}$. Rowinsky et $\mathrm{al}^{16}$ showed a decrease in mean nadir ANCs in a sequence-finding study. When cisplatin preceded paclitaxel, the nadir was significantly lower than in the reversed schedule. In that study, paclitaxel was administered as a 24 -hour infusion ( $4 \times 6$ hours). The schedule paclitaxel $135 \mathrm{mg} / \mathrm{m}^{2}$ and cisplatin $50 \mathrm{mg} / \mathrm{m}^{2}$ showed a mean nadir of $770 / \mu \mathrm{L}$ when platinum preceded paclitaxel and $1,002 / \mu \mathrm{L}$ when platinum followed paclitaxel administration. The schedule paclitaxel $135 \mathrm{mg} / \mathrm{m}^{2}$ plus cisplatin $75 \mathrm{mg} / \mathrm{m}^{2}$ resulted in ANC nadirs of $592 / \mu \mathrm{L}$ and $670 / \mu \mathrm{L}$ in the same sequence, respectively. This was explained by Rowinsky et $\mathrm{al}^{16}$ by a lower clearance when cisplatin preceded paclitaxel. Overall, mean paclitaxel clearance rates in Rowinsky's study were $19.26 \pm 2.64 \mathrm{~L} / \mathrm{h} / \mathrm{m}^{2}$ when paclitaxel followed cisplatin, and $24.3 \pm 3.9 \mathrm{~L} / \mathrm{h} / \mathrm{m}^{2}$ for the alternate sequence. The nadir ANC ( $135 \mathrm{mg} / \mathrm{m}^{2}, 24$ hours) in this study differs from that found by Rowinsky et al; our nadir, $360 / \mu \mathrm{L}(\mathrm{n}=2)$, was far lower than in their combination therapy with the same paclitaxel dosage, although the clearance was $22.97 \pm 5.86 \mathrm{~L} / \mathrm{h} / \mathrm{m}^{2}$. Since we found an overall lower nadir, a decrease in clearance would be expected, but was not found. However, a complete comparison with the study reported by Rowinsky et al is not possible, as relatively heavily pretreated patients were included in this study, whereas the patients reported by Rowinsky et al were less pretreated. In conclusion, clearance may not be a good estimator, but the duration of the plasma concentration above a threshold of $0.1 \mu \mathrm{mol} /$ $\mathrm{L}$ might be a better predictor of hematologic toxicity. As far as hematologic toxicity is concerned, future trials should be designed whereby the duration of plasma levels more than $0.1 \mu \mathrm{mol} / \mathrm{L}$ are minimized. A $50 \%$ decrease in ANC and WBC will be found when this time ranges from 11 to 15 hours.

In view of the chemical structure of paclitaxel and earlier reports about the detection of metabolites in rat and human bile, it was expected that metabolic products could be detected. However, metabolites were not identified in human plasma with the available techniques reported in literature..$^{3,14-20}$ In our study, we found 11 possible metabolites. By using on-line PDA detection, we found that the metabolites I, II, and V still contain the paclitaxel chromophore, as the spectra were similar to that of paclitaxel. The amounts of the other eight putative metabolites were too small to allow further analysis.

Hydroxylation of phenyl groups has been suggested to play an important role in metabolism. ${ }^{22,23}$ However, the results of UV-PDA analysis were not in accordance with this assumption. The spectra of the three major metabolites closely resembled the spectrum of paclitaxel without the specific changes in the spectrum that could be expected for a phenyl hydroxylation. Baccatin III, a natural precursor of paclitaxel with no $\mathrm{C}_{13}$ side chain, was not detected. This HPLC methodology is the most sensitive and selective technique for paclitaxel bioanalysis. The lack of sensitivity and the loss of the metabolites during the sample pretreatment in other assays are probably the reasons that others have not detected metabolites in plasma so far. Another reason is that earlier studies administered paclitaxel as a 6or 24-hour infusion. With these relatively long infusion durations, low paclitaxel peak levels and, consequently, low metabolite levels occur. However, with this method, we detected, although in small quantities, metabolites in several patients treated with a 24-hour infusion.

In this study, we tried to make a correlation between pharmacokinetics and pharmacodynamics; only a small 
number of patients were entered onto the study. For further optimization for the clinical use of paclitaxel, larger groups of patients have to be investigated in population pharmacodynamic and pharmacokinetic studies. For this purpose, limited sampling strategies are under investigation.

Hepatic metabolism, perhaps with hydroxylation reactions, probably plays a pivotal role in the metabolism and excretion of paclitaxel. Comedication with inductive or inhibitive effects on metabolic enzymes may influence these processes. Rowinsky et $\mathrm{al}^{16}$ have already found a sequence-dependent influence of cisplatin on paclitaxel with profound clinical consequences. Therefore, clinical trials are underway to evaluate further drug-drug interactions with paclitaxel.

\section{REFERENCES}

1. Cragg GM, Snader KM: Taxol: The supply issue. Cancer Cells 3:233-235, 1991

2. Horwitz SB: Mechanism of action of taxol. Trends Pharmacol Sci 13:134-136, 1992

3. Wiernik PH, Schwartz EL, Strauman JJ, et al: Phase I clinical and pharmacokinetic study of taxol. Cancer Res 47:2486-2493, 1987

4. Shiff PB, Horowitz SB: Tubulin: A target for chemotherapeutic agents, in Sartorelli AC, Lazo JS, Bertino JR (eds): Molecular Actions and Targets for Cancer Chemotherapeutic Agents. New York, NY, Academic, 1981, pp 483-507

5. Clinical Brochure: Taxol (NSC-125973). Bethesda, MD, National Cancer Institute, 1983

6. Rowinsky EK, Cazenave LA, Donehower RC: Taxol: A novel investigational antimicrotubule agent. J Natl Cancer Inst 82:12471259,1990

7. Donehower RC, Rowinsky EK, Grochow LB, et al: Phase I trial of taxol in patients with advanced malignancies. Cancer Treat Rep 71:1171-1177, 1987

8. Legha SS, Tenney DM, Krakhoff IR: Phase I study of taxol using a 5-day intermittent schedule. J Clin Oncol 5:1232-1239, 1987

9. Einzig AI, Hochster H, Wiernik PH, et al: A phase II study of taxol in patients with malignant melanoma. Invest New Drugs 9:5964, 1991

10. McGuire WP, Rowinsky EK, Rosenheim NB, et al: Taxol: A unique antineoplastic agent with significant activity in advanced ovarian epithelial neoplasm. Ann Intern Med 111:273-279, 1989

11. Einzig AI, Wiernik PH, Sasloff J, et al: Phase II study and long-term follow up of patients treated with taxol for advanced ovarian adenocarcinoma. J Clin Oncol 10:1748-1753, 1992

12. Einzig AI, Gorowski E, Sasloff J, et al: Phase II trial of taxol in patients with metastatic renal cell carcinoma. Cancer Invest 9: 133-136, 1991

13. Sarosy G, Kohn E, Stone DA, et al: Phase I study of taxol and granulocyte stimulating factor in patients with refractory ovarian cancer. J Clin Oncol 10:1165-1170, 1992

14. Wiernik PH, Schwartz EL, Einzig A, et al: Phase I trial of taxol given as a 24-hour infusion every 21 days: Responses seen in metastatic melanoma. J Clin Oncol 5:1232-1239, 1987
15. Grem JL, Tutsch KD, Simon KJ, et al: Phase I study of taxol administered as a short iv infusion daily for 5 days. Cancer Treat Rep 71:1179-1184, 1987

16. Rowinsky EK, Gilbert MR, McGuire WP, et al: Sequences of taxol and cisplatin: A phase I and pharmacologic study. J Clin Oncol 9:1692-1703, 1991

17. Rowinsky EK, Burke PJ, Karp JE, et al: Phase I and pharmacodynamic study of taxol in refractory acute leukemias. Cancer Res 49:4640-4647, 1989

18. Longnecker S, Ross D, Grochow L, et al: High performance liquid chromatographic assay for taxol in human plasma and urine and pharmacokinetics in a phase I trial. Cancer Treat Rep 71:53-59, 1987

19. Brown T, Havlin K, Weiss G, et al: Phase I trial of taxol given by a 6-hour intravenous infusion. J Clin Oncol 9:1261-1267, 1991

20. Rowinsky EK, Donehower RC: Clinical pharmacologic studies of the antimicrotubule agent taxol, in NCI-EORTC Symposium on New Drugs in Cancer Therapy. Amsterdam, the Netherlands March 17-20, 1992. Ann Oncol 3:242, 1992 (suppl 1, abstr)

21. Cragg G, Sufness M: Metabolism of plant-derived anticancer agents. Pharmacol Ther 37:425-461, 1988

22. Monsarrat B, Mariel E, Cros S, et al: Taxol metabolism. Isolation and identification of three major metabolites of taxol in rat bile. Drug Metab Dispos 18:895-901, 1990

23. Monsarrat B, Wright M, Dubois J, et al: Taxol metabolism in rat and human bile, in NCI-EORTC Symposium on New Drugs in Cancer Therapy. Amsterdam, the Netherlands March 17-20, 1992. Annal Oncol 3:258, 1992 (suppl 1, abstr)

24. Rizzo J, Riley C, von Hoff D, et al: Analysis of anticancer drugs in biological fluids: Determination of taxol with application to clinical pharmacokinetics. J Pharm Biomed Anal 8:159-164, 1990

25. Proost JH, Meijer DKF: MW/PHARM, an integrated software package for drug dosage regimen calculation and therapeutic drug monitoring. Comput Biol Med 22:155-163, 1992

26. Gibaldi M, Perrier D: Pharmacokinetics (ed 2). New York, NY, Dekker 1982, pp 409-417 